\title{
Autoinmunidad. De la medicina basada en los postulados de Virchow a las bases de una medicina basada en los postulados de la biología molecular y epidemiología molecular
}

\author{
F. BLASCO PATIÑO \\ Servicio de Medicina Interna. Unidad de Diagnóstico Médico. Hospital de Torrevieja. \\ Torrevieja, Alicante
}

\begin{abstract}
AUTOINMUNITY FROM THE MEDICINE BASED ON VIRCHOW'S POSTULATES TO THE MEDICINE BASED ON THE POSTULATES OF
\end{abstract} THE MOLECULAR BIOLOGY AND MOLECULAR EPIDEMIOLOGY

Blasco Patiño F. Autoinmunidad. Medicina basada en los postulados de Virchow a las bases de una medicina basada en los postulados de la biología molecular y epidemiología molecular. An Med Interna (Madrid) 2008; 25: 301-305.

\section{INTRODUCCIÓN}

Oppenheimer afirmaba: "Un científico debe tomarse la libertad de plantear cualquier cuestión, de dudar de cualquier afirmación, de corregir errores". Ésta es la base que nos lleva a formular hipótesis y a cuestionar la validez de ideas asentadas en el mundo científico. Una base errónea es el pilar para una concepción errónea.

Las enfermedades autoinmunes pueden ser el paradigma, en medicina, de esta afirmación. Así por ejemplo en las vasculitis, la clasificación actual aceptada se basa en conceptos meramente anatomopatológicos, es la medicina de la escuela de Virchow, "las enfermedades surgen no en los órganos o tejidos en general, sino, de forma primaria en células individuales" conceptos válidos ya hace mas de 100 años, y de poca utilidad en la clínica diaria. La epidemiología genética, y la epidemiología molecular, disciplinas en las que se establecen las interrelaciones entre los microorganismos y el sistema inmune, sobre una base genética, si bien cada vez forman parte de un mayor número de estudios, siguen siendo disciplinas marginales a la hora de afrontar el planteamiento de estos procesos.

Hace 5 años, publiqué en esta revista una hipótesis en la que se remarcaban la importancia que los agentes infecciosos iban a tener en las futuras investigaciones sobre autoinmunidad (1). Los estudios que van surgiendo comienzan a apoyar esta teoría, valga de ejemplo el reciente artículo de Abraham et al. (2). Sobre el papel del E. Coli invasivo en el desarrollo de la enfermedad de Crohn. De los diferentes mecanismos referidos en este primer articulo, el presente trabajo propone una hipótesis en base al modelo de reacción cruzada, sentando las bases de lo que debería ser un nuevo enfoque de muchas de estas enfermedades, basados en los preceptos de estas dos disciplinas, lo que sin duda conllevará la aparición de herramientas diagnósticas y el desarrollo de nuevas terapias.

\section{CONCEPTOS}

\section{BIOLOGÍA MOLECULAR}

La biología molecular concierne principalmente al entendimiento de las interacciones de los diferentes sistemas de la célula, lo que incluye muchísimas relaciones, entre ellas las del ADN con el ARN, la síntesis de proteínas, el metabolismo, y el cómo todas esas interacciones son reguladas para conseguir el funcionamiento de la célula.

\section{EPIDEMIOLOGÍA MOLECULAR}

Se ha redefinido como una ciencia que se centra en la contribución de factores de riesgo potenciales tanto genéticos como "ambientales" (fundamentalmente agentes infecciosos) 
-identificados a nivel molecular-, a la etiología, distribución y prevención de enfermedades dentro de las familias y en las poblaciones y se puede citar entre sus objetivos:

-El estudio analítico y descriptivo para el control de enfermedades de origen bacteriano, viral y parasitario a través del diagnóstico molecular.

- La prevención de enfermedades no transmisibles y desórdenes genéticos evaluando el riesgo e identificando individuos susceptibles a través de un screening genético.

\section{HIPÓTESIS GENERAL}

Para plantear la hipótesis general recurriré a la historia de una persona cualquiera, con muchas posibilidades de ser mujer, hasta este momento sana. Tiene una vida normal y sin la más mínima sospecha de que una herencia, herencia que recibió de sus padres hace dos o tres décadas, va a condicionar un cambio radical en la vida que conocía.

Un día nota una sensación distérmica, está más cansada pero no le da la mayor importancia, es uno de los muchos "catarros" que ha tenido a lo largo de su vida, sin embargo en esta ocasión es diferente, el microorganismo responsable conlleva una respuesta inusual de su organismo. Los Acs que ha generado están atacando a las células que conforman sus órganos. El agente agresor posee o genera, como respuesta a estímulos como la hipoxia o el calor, antígenos proteicos similares a otras proteínas que hay en su cuerpo, y lo que es peor, su organismo tiene el código que necesitan estos antígenos para que su sistema inmune se active. Si la situación se vuelve mala, peor aún es el hecho de que este antígeno es un superantígeno y no sólo responde al código sino que además no lo necesita, se une directamente a los linfocitos, multiplicando por diez mil la respuesta inflamatoria. Los sistemas de contención red idiotipo-antiidiotipo se ven desbordados y es imposible bloquear la cascada de Acs liberados y los fenómenos inflamatorios derivados de la liberación masiva de citoquinas. En pocos días, lo que parecía un catarro, se ha transformado en una respuesta inflamatoria multisistémica, que tendrá como foco de mayor intensidad el tejido o tejidos que poseen las proteínas que son molecularmente similares al antígeno que desencadeno la respuesta.

Determinar los antígenos desencadenantes, la proteína orgánica que se asemeja molecularmente a este antígeno, y el HLA que permite acoplarla, son las bases que deben condicionar estudios poblacionales amplios, que incluyan simultáneamente sujetos sanos y sujetos potencialmente enfermos. La determinación de estos parámetros permitirá diagnósticos certeros, no sólo en base a criterios médicos, y tratamientos dirigidos. El planteamiento de esta hipótesis, está realizado en base a una serie de hechos ampliamente demostrados en diversos estudios.

\section{DATOS EVIDENCIADOS EN LOS PROCESOS DE AUTOINMUNIDAD}

-Existencia de una base genética: en prácticamente la totalidad de las enfermedades de base autoinmune se ha descrito la existencia de un predominio de uno o varios subtipos de HLA, Sistema mayor de histocompatibilidad presente en la superficie de las células con capacidad de presentar antígenos al sistema inmune y poner en marcha la respuesta inmune.
Se trata de una proteína de estructura terciaria que le permite adoptar una conformación espacial única. Los distintos aminoácidos que la conforman siguen una determinada posición que les permite realizar enlaces covalentes que van dibujando la estructura espacial de la proteína. Esta estructura espacial permite que el antígeno se acople a ella como una llave a una cerradura.

Por lo tanto, la existencia de subtipos específicos de HLA, forzosamente implica la disposición de ese sistema inmune a reaccionar con determinados antígenos, internos o externos, y condicionar la activación de la respuesta inmune. Un ejemplo de la importancia de este hecho lo tenemos en la diabetes mellitus tipo 1. En algunos estudios se había venido observando la existencia de algunos alelos HLA DQB, concretamente el HLA DQB1* 0301 y 0302 que favorecían el desarrollo de diabetes. Morel et al. (3) observaron que el $96 \%$ de estos pacientes poseían un aminoácido neutro en la posición 57 de la cadena, mientras que aquellos que no desarrollaban diabetes y tenían el HLA DQB poseían un ácido aspártico en dicha posición lo cual les proporcionaba protección. Parece lógico pensar que esta alteración de la estructura terciaria de la proteína HLA modifica su capacidad para captar el antígeno. El cambio de un solo aminoácido de la estructura primaria conlleva la alteración de los enlaces covalentes existentes entre aminoácidos y que determina la conformación espacial de la proteína.

- Amplio predominio en el sexo femenino: es un hecho estadístico que existe una preponderancia de las enfermedades autoinmunes en el sexo femenino. Y la única diferencia que podría explicar esto, es la única diferencia biológica que existe entre ambos, las hormonas circulantes. ¿Qué papel podrían jugar los estrógenos o la progesterona? En algunas enfermedades existen estudios que demuestran una clara elevación de los niveles de estrógenos con respecto a la población sana, incluso en hombres con artritis reumatoide (4) tambien se ha descrito en la arteritis de Takayasu, si bien la explicación dada en este caso es que el estradiol condiciona el aumento de la adhesividad al endotelio vascular de las células inflamatorias5 Pero tal vez más importante sea el hecho de que los estrógenos estimulan los linfocitos T, B, macrófagos, y sobre todo la expresión de moléculas HLA y de adhesión (6). Un mayor número de moléculas HLA tipo II y una mayor reactividad de los linfocitos puede determinar que bajas dosis de Antígenos desencadenen la respuesta inmunológica.

-Importancia de los microorganismos en el desarrollo de autoinmunidad: epidemiología molecular. La asociación entre infección y autoinmunidad no es un concepto que haya surgido en los últimos años. Esta se ha evidenciado desde hace décadas, el ejemplo clásico es la relación entre la infección por Streptococo del grupo A y la fiebre reumática. En 1968 Gobstein y cols. (7) publicaron en Nature la existencia de anticuerpos dirigidos contra polisacáridos del Streptococo del grupo A que reaccionaban de forma cruzada por su similitud antigénica con una glicoproteína situada en las válvulas cardiacas humanas y bovinas. En ese mismo año Sandson y cols. (8) describen la similitud entre la hialuronidasa de la cápsula del Streptococo del grupo A y el tejido conectivo humano, esta respuesta se daba más en sujetos con HLA A5, atribuyendo varios autores esta asociación a una selección genética de la respuesta inmune frente a determinados antígenos estreptococicos. 
El modelo descrito es el denominado modelo de reacción cruzada. Esta forma de respuesta autoinmune esta adquiriendo cada vez mayor importancia. Lunardi y cols. (9) evidenciaron en 10 pacientes que cursaban con episodios de artritis simétrica catalogados como artritis reumatoide, la existencia de Acs (anticuerpos) IgM frente a parvovirus B-19, indicador de infección aguda por este virus. Los autores del trabajo sintetizaron anticuerpos frente a este germen tomando como base péptidos víricos obtenidos de la región que codificaba la proteína 1 y 2 del virus. En una segunda fase, cruzaron los anticuerpos obtenidos con células humanas, reconociendo y fijando queratina, colágeno tipo 2, DNA monocatenario y cardiolipina. En esta misma línea Hemmerich y cols. (10) han demostrado la relación existente entre lupus eritematoso sistémico (LES) y la enfermedad mixta del tejido conectivo (EMTC) con la infección por Clamydia tracomatis. Los autores de este trabajo evidenciaron una alta homogeneidad entre la secuencia 264-286 de la RNA polimerasa de la Clamydia y la proteína ribosomial L7.

-Importancia de los Superantigenos: los superantígenos son moléculas, principalmente derivadas de virus, bacterias o parásitos, que interactúan con al menos dos receptores expresados sobre diferentes células (11). Las moléculas del complejo principal de histocompatibilidad de tipo II (CPH-II) que se expresan primariamente en células presentadoras de antígenos (CPAs) son empleadas como receptores por los superantígenos. Una característica especial y única de los superantígenos, a diferencia de los antígenos convencionales, es que no requieren el procesamiento por una $\mathrm{CPA}$, y además pueden interaccionar con un elevado número de células $\mathrm{T}$.

Normalmente, los antígenos convencionales son procesados en pequeños péptidos en el endosoma de la CPA. Estos péptidos forman complejos con moléculas del complejo principal de histocompatibilidad tipo II (CPH-II), los cuales son transportados a la superficie celular de la CPA donde interaccionan con los receptores de los linfocitos $\mathrm{T}$ colaboradores (RCT), que reconocen este complejo, lo que se traduce en la producción de citoquinas. En contraste, el superantígeno enlaza directamente al CPH-II presente en la superficie de la CPA y a una parte del receptor presente en el linfocito $\mathrm{T}$, independientemente de la especificidad del RCT. De esta forma, en comparación con los antígenos tradicionales que pueden interactuar con una célula de cada 10.000-1.000.000 linfocitos T, los superantígenos son capaces de interactuar con 5-20 de cada 100 células T. Ciertos superantígenos pueden activar y dirigir a células T para eliminar células que expresan moléculas CPH-II (12). Este fenómeno se denominó citotoxicidad celular dependiente de superantígeno (CCDS), e incluye únicamente a ciertos grupos de linfocitos T (CD4 y CD8). La estructura diana del fenómeno CCDS son las moléculas del CPH-II (13). Por tanto, la destrucción preferencial de células que tienen en su superficie moléculas del CPH-II pueden implicar la destrucción de potenciales células presentadoras de antígeno, lo que implicaría una disminución de las reacciones inmunes, incluyendo aquellas que están dirigidas contra el patógeno.

- El papel de las proteínas de Estrés: este grupo de proteínas es producido por tejidos animales o microorganismos expuestos a situaciones de estrés, como el calor, anoxia o células infectadas por virus. Se clasifican en función de su peso molecular, y su función es adaptar a la célula o al microorganismo frente a estas situaciones de estrés. En este último caso puede ser común a muchos microorganismos diferentes, bacterias Gram positivas, Gram negativas e incluso Mycobacteria. La mas importante es la $65-\mathrm{KDa}$, inicialmente identificada en $M$. leprae. El hecho más importante es que se comporta como un antígeno, habiéndose comprobado la capacidad de inducir en ratas fenómenos similares a la artritis reumatoide humana (14) Lehner et al. (15) comprobaron como en pacientes con Síndrome de Behçet existía una elevación significativa de los Acs IgA frente a la proteína $65 \mathrm{~K}$-Da y Acs frente a la proteína soluble de los $\mathrm{S}$ sanguis ST3, KTH-1, KTH-2y KTH-3, lo que apoya la hipótesis de que algunos Ag estreptocócicos son en realidad proteínas de stress con capacidad antigénica en sujetos susceptibles.

\section{DATOS DISCUTIBLES}

- Considerar las enfermedades como procesos inconexos con mecanismos de origen diferentes. Existe una parcelación de las enfermedades autoinmunes, con especialistas de las diversas ramas de la medicina que canalizan el trabajo a determinados procesos, sin que exista interconexión con los hallazgos aportados en la investigación de otras patologías. No existe el mismo enfoque para una persona con Guillain-Barre, Esclerosis Múltiple, Tiroiditis de Hashimoto, cirrosis biliar primaria, o artritis reumatoide. Estos procesos por difícil que sea creerlo tienen mas en cosas en común que en su contra, sin embargo no son estudiados desde un mismo enfoque. Algunos ejemplos de Patologías modelo

- Síndrome de Cogan: enfermedad autoinmune que cursa con inflamación del ojo, y del oído interno. Una tercera parte de los pacientes presentan infección del tracto respiratorio superior previa a la aparición de la clínica, otros diarrea o vacunación reciente (16). La proteína diana es probablemente un receptor de membrana localizado en células del endotelio, oído interno, células epiteliales del ojo, y fibroblastos, denominado DEP-1/CD148. Esta proteína intervendría en procesos de crecimiento y diferenciación molecular. Muestra similitud antigénica con la conexina 26, proteína del epitelio neurosensorial el oído interno que interviene en procesos de comunicación intercelular. El Agente infeccioso probablemente implicado sería el Reovirus III, cuya infección se asocia a fiebre, rinitis y faringitis. La proteina Lambda 1 de este virus, muestra similitud antigénica con las dos proteinas anteriormente descritas. Lunardi et al. (17) aislaron autoanticuerpos purificados en pacientes con este síndrome, y demostraron el mecanismo autoinmune de la enfermedad mediante dos experimentos. Uno al provocar en un modelo murino la perdida de audición al transferir estos Acs, y el segundo al identificar un péptido en el organismo que reconocía estos anticuerpos (Péptido de Cogan), con marcada similitud antigénica tanto con la proteína Lambda como con las proteínas conexina 26 y DEP1/CD148. La susceptibilidad genética vendría dado por variantes del HLA A9 y Bw17.

-Enfermedad de Behçet: Enfermedad autoinmune que cursa con inflamación de la mucosa oral, genital, ocular, pudiendo tener también afectación meníngea, articular y vascular. La proteína diana es probablemente un antígeno de la mucosa oral, el Antigeno mitoconcrial humano P1 (AMH P1). Mediante técnicas de epidemiología molecular se han identificado varios serotipos de $\mathrm{S}$. sanguis KTH1, 2 y 3, como responsables de desencadenar la respuesta autoinmune. En un trabajo publicado por Lehner et al, demostraron una reacción 
cruzada entre estos serotipos de $\mathrm{S}$ sanguis y la proteina de stress $65 \mathrm{Kda}$. A su vez existe una reacción cruzada entre el antígeno mitocondrial humano P1 de la mucosa fetal oral y la proteína de stress 65-kDa (15).

De esta forma es probable que en el contexto de una infección por estos serotipos de S. sanguis, en determinadas situaciones se produzca la liberación de proteínas de stress similares a la 65-kDa. En sujetos con una base genética principalmente en presencia de variantes de HLA B51 y el MIC A6, este antígeno es reconocido y condiciona la liberación de Acs dirigidos contra esta proteína y contra las proteínas con similitud antigénica AMH P1

- Síndrome de Guillain Barre: enfermedad autoinmune con base en el sistema nervioso periférico. El cuadro se desarrolla en días tras un proceso infeccioso gastrointestinal, respiratorio o vacunación frente a diversos microorganismos, coincidiendo con la elevación de los Acs en la sangre. La proteína diana se localiza en los gangliosidos que conforman las vainas de mielina. Yuki y cols. (18) estudiaron un grupo de 8 pacientes con SGB y antecedentes de gastroenteritis en los días previos. En 4 de ellos demostraron infección aguda por esta bacteria. Valiéndose de test de inmunoabsorción realizados sobre el serotipo HS-19, observaron la presencia en polisacáridos de la cápsula de C.jejuni, del epítope Ga1NacGD1a, presente en gangliósidos que forman parte de la estructura de nervios periféricos, y probable responsable del mecanismo de respuesta cruzada. Además de $\mathrm{C}$ jejuni se han relacionado otros microorganismos, o tras vacunas. Existiendo una susceptibilidad genética en sujetos HLA B35, HLA DQB1 03 DQB1 06, DRB 1301 y 1303, dependiendo la asociación si se trata de una forma axonal o la desmielinizante, y probablemente habría que realizar estudios de la correspondencia de estos HLA con los diferentes microorganismo descritos (19). El 26-41\% de los casos de SGB20 e incluso el $66 \%$ de los estudios realizados en China (21) atribuyen a $C$. jejuni el origen, de este cuadro.

- Establecer a partir de los hallazgos obtenidos de los estudios inmunológicos de pacientes enfermos, conclusiones en los que el efecto es considerado como causa. Dificultad para obtener datos del sistema inmune basal antes de enfermar.
Es un hecho admitido el atribuir al LES la existencia de una predisposición genética a una estimulación excesiva de los linfocitos B, por una anomalía de control que sobre ellas ejerce subpoblaciones de linfocitos $\mathrm{T}$, y una respuesta excesiva frente a antígenos linfocitarios o nucleares (22). Pero estos estudios están hechos sobre pacientes enfermos con lupus, nada se sabe de su sistema inmune antes de enfermar, es imposible afirmar que estos cambios no son la respuesta a la tormenta de citoquinas desencadenada tras la estimulación del sistema inmune.

En la migración de los linfocitos hacia focos inflamatorios es un fenómeno en el que participan múltiples moléculas de adhesión, atracción y de activación siguiendo una secuencia previa y concertada, estas moléculas son proteinas englobadas en la familia de las selectinas, integrinas, mucinas, cadherinas etc23 El ataque de Acs sobre estas proteínas podría condicionar una alteración en los fenómenos de migración y un aumento de subpoblaciones de linfocitos con el consecuente desequilibrio en la balanza del sistema inmunológico.

Se hacen precisos estudios de carácter prospectivo, al alcance de muy pocos, que impliquen amplias poblaciones de sujetos, sanos en el momento del inicio del estudio, lo cual dificulta en gran medida su realización, que permita obtener muestras de los sujetos en un momento en el que la enfermedad no ha desestructurado al sistema inmune, y en los que se empleen técnicas de epidemiología y genética molecular con el fin de identificar los antígenos desencadenantes y sus interrelaciones con el sistema inmunológico. La comprensión de la enfermedad pasa por comprender los cambios que se han producido en el sujeto previamente sano.
"El futuro tiene muchos nombres. Para los débiles es lo inalcanzable. Para los temerosos, lo desconocido. Para los valientes es la oportunidad"

Víctor Hugo

\section{Bibliografía}

1. Blasco F. La infección como origen y desencadenante de enfermedades autoinmunes. An Med Interna (Madrid) 2002; 19: 44-8.

2. Abraham C, Cho JH. Bugging of the Intestinal Mucosa. N Engl J Med 2007; 357: 708-10.

3. Morel PA, Dorman JS, Todd JA, Mc Devitt HO, Trucco M. Aspartic Acid at position 57 of the HLA DQB chain protects against type 1 diabetes: A family study. Proc Natl Acad Sci USA 1988; 85; 3111-5.

4. Tengstrand B, Carlström K, Felländer-Tsai L, Hafström I. Abnormal Levels of Serum Dehydroepiandrosterone, Estrone, and Estradiol in Men with RA: High Correlation Between Serum Estradiol and Current Degree of Inflammation. J Rheumatol 2003; 30: 2338-43.

5. Cid MC, Kleinman HK, Grant DS, Schnaper HW, Fauci AS, Hoffman GS. Estradiol enhances leukocyte binding to tumor necrosis factor (TNF)-stimulated endothelial cells via an increase in TNF-indu- ced adhesion molecules E-selectin, intercellular adhesion molecule type 1, and vascular cell adhesion molecule type 1. J Clin Invest 1994; 93: 17-25.

6. Tabibzadeh SS, Sivarajah A, Carpenter D, Ohlsson-Wilhelm BM, Satyaswaroop PG. Modulation of HLA-DR expression in epithelial cells by interleukin 1 and estradiol-17 beta. J Clin Endocrinol Metab 1990; 71: 740-7.

7. Gobstein I, Rebeyotte P, Parlebas J, et al. Isolation front heart valves of glycopeptides which share immunological properties which Streptococcus haemolyticus group A polysaccharides. Nature 1968; 219: 286.

8. Sandson J, Hamuman D, Janis R, et al. Inmunologic and chemical similarities between the streptococcus and human connective tissue. Trass Assoc Am Phys 1968; 81: 249. 
9. Lunardi C, Tiso M, Borgato L, Nanni L, Millo R, De Sandre G, et al. Chronic Parvovirus B-19 infection induces the production of antivirus antibodies with autoantigen binding properties. Eur J Inmunol 1998; 28: 3857-66

10. Hemmerich P, Neu E, Mach M, Peter HH, Kraveinvel U, Von Mikecz A. Correlation between Chlamydia infection and autoinmune response: molecular mimicry between RNA Polymerase major sigma subunit from Chlamydia trachomatis and human L7. Eur J Inmunol. 1998; 28: 3857-66.

11. Chatila T, Geha Rs. Superantigens. Curr Opin Immunol. 1992; 4: 74-8.

12. Dohlsten M, Hedlund G, Kalland T. Staphylococcal-enterotoxindependent cell-mediated cytotoxicity. Immunol 1991; 12: 147-50.

13. Dohlsten M, Hedlund G, Segren S, Lando PA, Herrmann T, Kelly AP, Kalland T. Human major histocompatibility complex class IInegative colon carcinoma cells present staphylococcal superantigens to cytotoxic T lymphocytes: evidence for a novel enterotoxin receptor. Eur J Immunol 1991; 21: 1229-33.

14. Van Eden W, Thole R, Van der Zee A, Noordzij JD, Van Embden EJ, et al. Cloning of the mycobacterial epitope recognized by $\mathrm{T}$ lymphocytes in adjuvant artritis. Nature 1998; 331: 171-3.

15. Lehner T, Lavery E, Smith R, Van der Zee R, Mizushima Y, Shinninck T. Association between the 65-Kilodalton Heat Shock Protein, Streptococous sanguis and the corresponding antibodies in Behçet's syndrome. Infect. Inmunnol 1991; 59: 1434-41.
16. Grasland A, Pouchot J, Hachulla E, Blétry O, Papo T, Vinceneux P, Typical and atipical Cogan's syndrome: 32 cases and review of the literaturae. Rheumatology 2004; 42: 1-9.

17. Lunardi C, Bason C, Leandri M. Autoantibodies to inner ear and endothelial antigens in Cogan's syndrome. Lancet 2002; 360: 91 921.

18. Yuki N, Taki T. Honda S. Antibody to Ga1Nac-GD1a and Ga1NacGM1c in Guillain-Barré Syndrome subsequent to Campylobacter jejuni. J Neuroinmunol 1996; 71: 155-61.

19. Rees AH, Vaugham RW, Kondeatis E, Hughes RAC. HLA-class II alleles in Guillain Barré syndrome and Miller Fisher syndrome and their association with preceeding Campylobacter jejuni infection. J Neuroinmunol 1995; 62: 53-7.

20. Jacob BC, van Doorm PA, Schmitz PM, et al. Campylobacter jejuni infections and anti GM1 antibodies and Guillain-Barré syndrome. Ann Neurol 1996; 40: 181-7.

21. Ho TW, Mishu B, Li CY, et al. Guillain Barré Syndrome in northem China. Relationships to Campylobacter jejuni infection and anti-glycolipid antibodies. Brain 1995; 118: 597-605.

22. Miret C, Espinosa G, Cervera R, Font J. Lupus Eritematoso Sistémico. En: Enfermedades Autoinmunes Sistemicas. Font J, Cervera R Ingelmo M Editores. Editorial MRA, Barcelona; 1998. p. 79-119.

23. Hatzfeld M. The p120 family of cell adhesion molecules. Eur J Cell Biol 2005; 84: 205-14. 